\title{
Uneven double-Iumen cannula for rescue guidewire technique in endoscopic ultrasonography-guided hepaticogastrostomy
}

Endoscopic ultrasonography-guided hepaticogastrostomy (EUS-HGS) is used after failed endoscopic retrograde cholangiopancreatography (ERCP) [1]. Manipulation of the guidewire is one of the most challenging techniques in EUSHGS. We present a successful case of rescue guidewire technique using a multilumen catheter [2], namely an uneven double-lumen cannula (Piolax Medical Devices, Yokohama, Kanagawa, Japan) (» Fig. 1), for EUS-HGS.

A 75-year-old man was admitted with obstructive jaundice due to advanced coIon cancer, after right hepatectomy for liver metastasis. We attempted EUS-HGS after failed ERCP. After the left intrahepatic bile duct had been punctured using a 19-gauge needle ( $\mathbf{F i g . 2}$ ), a 0.025-inch hard-type guidewire (VisiGlide 2; Olympus, Tokyo, Japan) was placed. The guidewire was accidentally introduced into the peripheral bile duct ( Fig.3). We then inserted the ERCP catheter along the guidewire into the left intrahepatic bile duct. However, the guidewire could not be advanced to the perihilar bile duct, even after we changed to a 0.032-inch hydrophilic guidewire (Radifocus; Terumo, Tokyo, Japan). Therefore, we coiled the 0.025 -inch hard-type guidewire again within the left intrahepatic bile duct, and changed the ERCP catheter to the uneven double-lumen cannula ( Video 1 ). This cannula was slowly withdrawn, and we were able to successfully introduce a second 0.032-inch hydrophilic guidewire to the perihilar bile duct via the 0.035-inch lumen ( Fig.4, Video 1). After changing to the hard-type guidewire ( $\mathbf{F i g . 5 , ~}>$ Video 1), a 7-Fr plastic stent (TYPE-IT; Gadelius Medical, Tokyo, Japan) was placed for EUS-HGS without complications (> Fig.6, \Video 1 ).

In EUS-HGS, the angle at which the intrahepatic bile duct is punctured is the most important factor in successful advance- ment of the guidewire toward the perihilar bile duct [3]. This depends on individual anatomy, and therefore it is sometimes difficult to achieve the optimal angle for advancing the guidewire to the perihilar bile duct. The uneven doublelumen cannula facilitated guidewire manipulation during EUS-HGS when it was difficult to direct the guidewire toward the perihilar bile duct.

Endoscopy_UCTN_Code_TTT_1AS_2AD

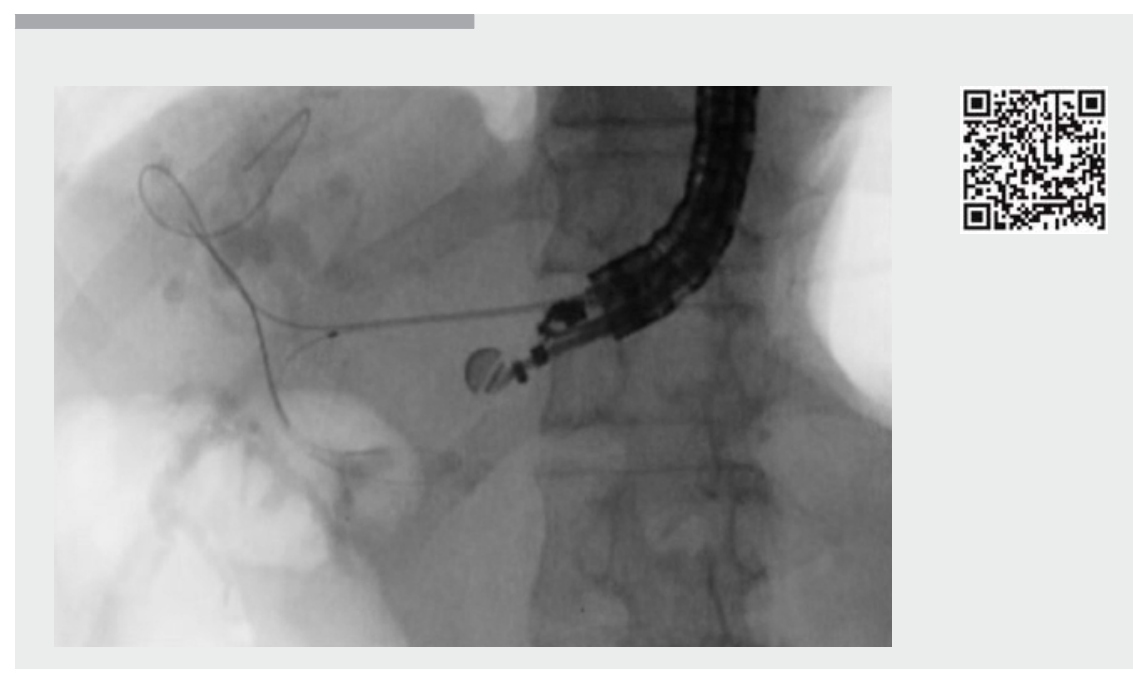

Video 1 New rescue technique using the uneven double-lumen cannula in order to direct a guidewire toward the perihilar bile duct for endoscopic ultrasonography-guided hepaticogastrostomy.

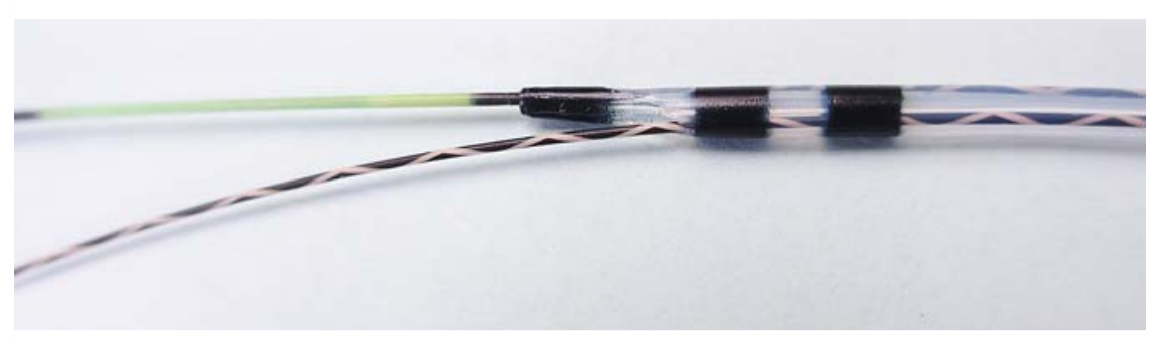

- Fig. 1 The uneven double-lumen cannula (short type; Piolax Medical Devices) has a distal port, with a radiopaque marker, for the 0.025 -inch guidewire lumen and a proximal port for the 0.035 -inch guidewire lumen. The catheter is tapered, with outer diameter $3.6 \mathrm{Fr}$ at the distal port and the maximum $6 \mathrm{Fr}$ at the proximal port and a length of $5 \mathrm{~mm}$ between the ports. 


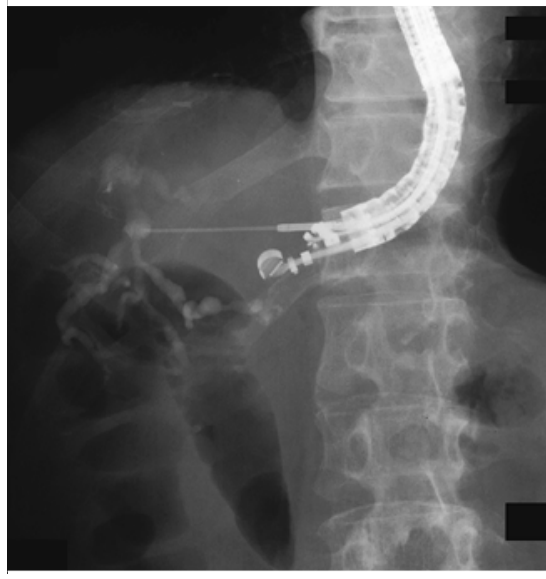

Fig. 2 Needle puncture of the left intrahepatic bile duct for endoscopic ultrasonography-guided hepaticogastrostomy (EUS-HGS) in a 75-year-old man with obstructive jaundice due to advanced colon cancer, after right hepatectomy for liver metastasis.

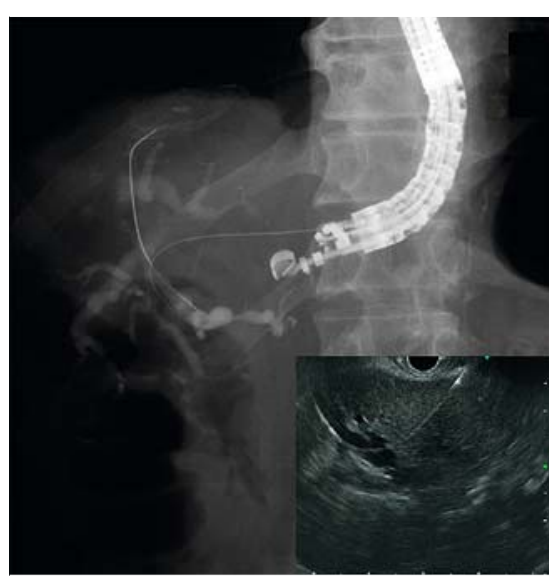

- Fig. 3 Accidental introduction of the guidewire into the peripheral bile duct. (Inset: endoscopic ultrasonography image.)

Hiroshi Kawakami ${ }^{1,2}$, Yoshimasa Kubota ${ }^{1,2}$, Hiroaki Makiyama ${ }^{3}$, Shinji Sato ${ }^{3}$, Tesshin Ban ${ }^{1,2}$

1 Department of Gastroenterology and Hepatology, Faculty of Medicine, University of Miyazaki, Miyazaki, Japan

2 Center for Digestive Disease, University of Miyazaki Hospital, Miyazaki, Japan

3 Department of Gastroenterology and Endoscopy, Shin-Yurigaoka General Hospital, Kawasaki, Kanagawa, Japan

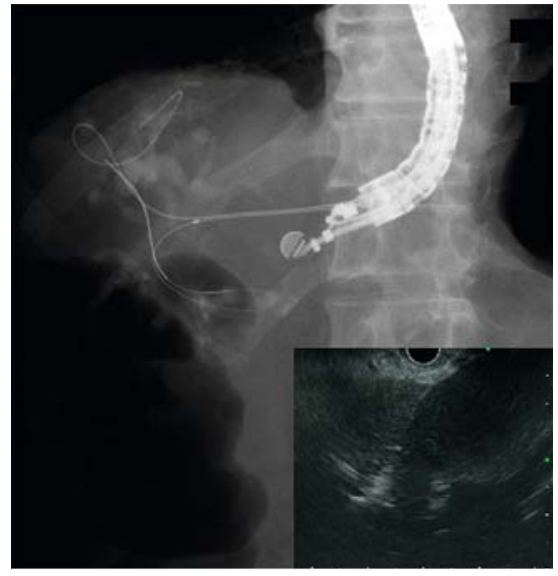

- Fig. 4 Guidewire inserted via the 0.025 -inch guidewire lumen of an uneven double-lumen cannula into the left intrahepatic bile duct, and a second 0.032 -inch hydrophilic guidewire advanced into the perihilar bile duct via the 0.035 -inch guidewire lumen. (Inset: endoscopic ultrasonography image.)

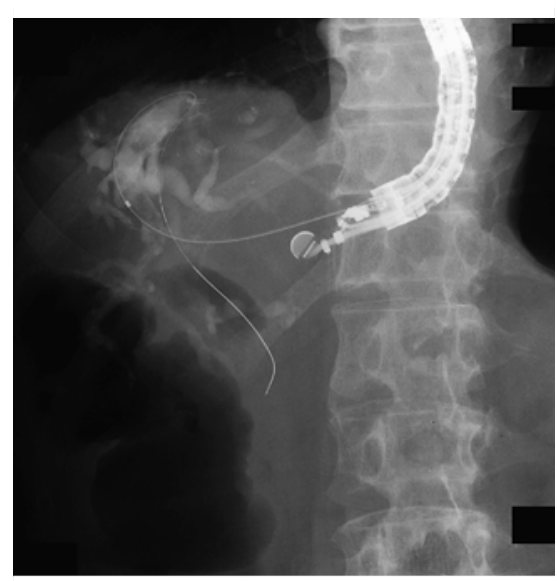

- Fig. 5 Changing the 0.032 -inch hydrophilic guidewire to the 0.025 -inch hardtype guidewire via the 0.035 -inch guidewire lumen of an uneven double-lumen cannula.

\section{Corresponding author}

\section{Hiroshi Kawakami, MD, PhD \\ Department of Gastroenterology and Hepatology, Faculty of Medicine, University of Miyazaki, Center for Digestive Disease, University of Miyazaki Hospital, 5200 Kihara, Kiyotake, Miayzaki 889-1692, Japan Fax: +81-985-859802 hiropon@med.miyazaki-u.ac.jp}

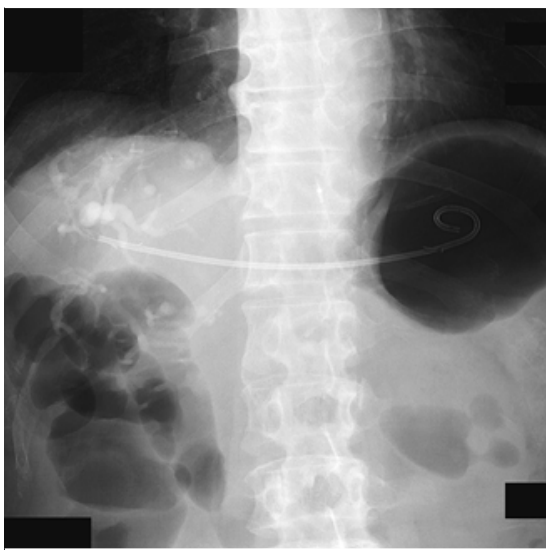

Fig. 6 A 7-Fr dedicated plastic stent in position in the left intrahepatic bile duct.

\section{References}

[1] Kawakubo K, Isayama H, Kato H et al. Multicenter retrospective study of endoscopic ultrasound-guided biliary drainage for malignant biliary obstruction in Japan. J Hepatobiliary Pancreat Sci 2014; 21: 328-334

[2] Kawakami H, Itoi T, Kuwatani M et al. Technical tips and troubleshooting of endoscopic biliary drainage for unresectable malignant hilar biliary obstruction. J Hepatobiliary Pancreat Sci 2015; 22: E12-E21

[3] Ogura T, Higuchi K. Technical tips for endoscopic ultrasound-guided hepaticogastrostomy. World J Gastroenterol 2016; 22: 3945-3951

\section{Bibliography}

DOI https://doi.org/10.1055/s-0043-116014

Published online: 31.7.2017

Endoscopy 2017; 49: E264-E265

(c) Georg Thieme Verlag KG

Stuttgart · New York

ISSN 0013-726X

\section{ENDOSCOPY E-VIDEOS}

https://eref.thieme.de/e-videos

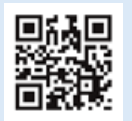

Endoscopy E-Videos is a free access online section, reporting on interesting cases and new techniques in gastroenterological endoscopy. All papers include a high quality video and all contributions are freely accessible online.

This section has its own submission website at

https://mc.manuscriptcentral.com/e-videos 